\title{
SOSIALISASI KELENGKAPAN DOKUMEN REKAM MEDIS RAWAT JALAN DI PUSKESMAS ANDALAS KOTA PADANG
}

\section{SOCIALIZATION THE COMPLETENESS OF OUTPATIENT MEDICAL RECORD DOCUMENTS AT ANDALAS PUBLIC HEALTH CENTER}

\author{
Nurhasanah Nasution* \\ Program Studi Ilmu Rekam Medis, Apikes Iris Padang \\ email: hasanah.nasution11@gmail.com
}

\begin{abstract}
ABSTRAK
Setiap fasilitas kesehatan baik dari tingkat primer, sekunder, tresier wajib menyelenggarakan rekam medis dengan tujuan untuk tercapainya tertib administrasi, pendokumentasian pelayanan yang telah diberikan oleh tenaga kesehatan kepada pasien salah satunya Puskesmas sebagai bentuk layanan tingkat pratama bagi pasien. Pengabdian Kepada Masyarakat (PKM) ini bertujuan untuk meningkatkan pemahaman petugas rekam medis dalam hal kelengkapan isi rekam medis di Puskesmas Andalas Kota Padang. Sosialisasi tentang kelengkapan isi rekam medis ini telah dilaksanakan pada hari Jum'at tanggal 6 Maret 2020, yang diikuti sebanyak 15 orang peserta yang terdiri dari dokter, petugas rekam medis dan staf puskesmas. Berdasarkan evaluasi dari kegiatan yang dilakukan, petugas rekam medis di puskesmas Andalas mendapatkan beberapa informasi baru terkait dengan kelengkapan isi rekam medis, dan dapat melengkapi beberapa formulir yang masih kurang didalam map rekam medis.
\end{abstract}

Kata kunci: Sosialisasi, Kelengkapan, Rekam medis, Dokumen, Puskesmas

\section{ABSTRACT}

Every health facility from primary, secondary, and secondary levels must organize medical records with the aim of achieving orderely administration, documentation, of sevices that has been given by health workers for patients, which is the public health center as a form of first-rate service for patients. This Community Services aims to increase the knowledges of medical records officers in terms of completeness of the contents of the medical record at Andalas Public Health Center in Padang City. This activity has conducted on Friday 6 March 2020, attended by 15 participants consisting of doctors, medical record officers dan other staff. Based on evaluation of the activity, medical record officers get some new information related tu the complete content of medical record, and can complete some forms that are still lacking in the medical record folder.

Keywords: Socialization, Completeness, Medical record, Documents, Public health center

\section{PENDAHULUAN}

Setiap fasilitas kesehatan baik dari tingkat primer/ pratama, sekunder, tresier wajib menyelenggarakan rekam medis dengan tujuan untuk tercapainya tertib administrasi, pendokumentasian pelayanan yang telah diberikan oleh tenaga kesehatan kepada pasien salah satunya Puskesmas sebagai bentuk layanan tingkat pratama bagi pasien. Puskesmas merupakan fasilitas pelayanan kesehatan tingkat pertama yang berperan penting dalam meningkatkan aksesibilitas, keterjangkauan, dan kualitas pelayanan dalam rangka meningkatkan derajat kesehatan masyarakat serta menyukseskan program jaminan kesehatan. Penyelenggaraan rekam medis wajib dibuat secara lengkap dan akurat [1] sehingga data Rekam Medis menjadi informasi yang komprehensif untuk pengambilan keputusan.

Rekam medis merupakan salah satu bagian penting dalam membantu pelaksanaan pemberian pelayanan kepada pasien di 
Puskesmas. Hal ini berkaitan dengan isi rekam medis yang mencerminkan segala informasi menyangkut pasien sebagai dasar dalam menentukan tindakan lebih lanjut dalam upaya pelayanan maupun tindakan medis lain.

Isi Rekam Medis merupakan berkas dokumen yang menunjukkan kesinambungan perawatan atau pengobatan selama pasien di rawat inap hingga rawat jalan, sebagai dokumen yang memperlihatkan komunikasi antar dokter penanggungjawab pasien dan dokter konsulan atau tenaga kesehatan lainnya dan sebagai dokumen pemberi kewenangan kepada tenaga medis atau kesehatan untuk melakukan tindakan medis [2].

Dokumen yang lengkap merupakan dokumen rekam medis yang telah diisi lengkap oleh dokter dalam waktu 2x24 jam setelah selesai pelayanan/ setelah pasien rawat inap diputuskan untuk pulang yaitu meliputi identitas pasien, anamnesis, rencana asuhan, pelaksanaan asuhan, tindak lanjut dan resume. Rekam medis yang lengkap didapat informasi-informasi yang dapat digunakan untuk berbagai keperluan [3].

Kelengkapan dokumen rekam medis sangat berpengaruh terhadap proses pelayanan yang dilakukan oleh petugas medis dan dapat mempengaruhi kualitas serta mutu dari pelayanan suatu sarana pelayanan kesehatan [4]. Indikator mutu rekam medis yang baik dan lengkap salah satunya adalah kelengkapan isi dan pemenuhan aspek persyaratan hukum. Rekam medis yang baik dapat mencerminkan praktik kedokteran yang baik selain itu juga menunjukkan kedayagunaan dan ketepatgunaan perawatan pasien [5].
Puskesmas Andalas merupakan salah satu puskesmas yang berada di Kota Padang yang memiliki 66 orang tenaga kesehatan yang bertugas di gedung induk, puskesmas pembantu dan pokelkel. Dari 66 tenaga kesehatan 3 diantarnya merupakan tenaga rekam medis yang terdiri dari 2 orang lulusan diploma dan satu orang volunteer [6].

Puskesmas Andalas menerima lebih dari 250 pasien setiap harinya. Berdasarkan perbandingan jumlah tenaga rekam medis dengan jumlah pasien yang diterima setiap hari dapat mempengaruhi kinerja petugas rekam medis dalam memenuhi kelengkapan berkas rekam medis. Berkas rekam medis yang menumpuk dan tidak tertata dengan rapi juga menjadi permasalahan dalam penyimpanan. Oleh karena itu, penulis tertarik untuk melakukan sosialisasi mengenai kelengkapan dokumen rekam medis rawat jalan di Puskesmas Andalas Kota Padang.

Sosialisasi ini dilakukan dengan sasaran utama yaitu petugas rekam medis di Puskesmas Andalas, mengingat segala informasi yang terkait dengan pasien dalam rekam medis seluruhnya dibawah tanggungjawab dari petugas rekam medis dan institusi terkait.

Sosialisasi ini bertujuan untuk berbagi pengetahuan terkait dengan kelengkapan isi rekam medis dan menjelaskan beberapa teoriteori yang penting dalam ilmu rekam medis yang dipelajari di kampus Apikes Iris.

\section{METODE PELAKSANAAN KEGIATAN}

PKM ini dilakukan dimulai dari persiapan, survey lokasi, pengumpulan bahan dan pembuatan materi sosialisasi. Dalam kegiatan 
pengabdian kepada masyarakat ini metode yang digunakan adalah memberikan sosialisasi bagaimana seharusnya isi berkas rekam medis dan kelangkapannya di Puskesmas Andalas Kota Padang Padang. Tim PKM memberikan penyuluhan bagaimana berkas rekam medis yang baik dan memberikan item-item yang harus ada pada berkas rekam kepada petugas rekam medis yang bertugas di Puskesmas Andalas Kota Padang. Tim PKM juga membawa contoh berkas Rekam Medis yang baik dan lengkap yang diambil dari laboratorium rekam medis Apikes Iris.

\section{HASIL DAN PEMBAHASAN}

Pengabdian kepada Masyarakat (PKM) ini telah dilaksanakan pada hari Jum'at tanggal 06 Maret 2020 di Puskesmas Andalas Kota Padang. Tim hibah PKM terdiri dari 3 orang, yang terdiri dari dua orang dosen dan satu orang mahasiswa. Peserta yang hadir sebanyak 15 orang yang terdiri dari Kabag humas, kepala rekam medis dan petugas rekam medis puskesmas Andalas.

Pada awal kegiatan, moderator memperkenalkan diri, kemudian setelah itu moderator memberikan penjelasan sedikit tentang pengabdian masyarakat yang dilakukan oleh tim hibah PKM Apikes Iris, kemudian moderator memberikan waktu untuk peserta untuk melaksanakan pre-test. Waktu dalam pengerjaan pre-test dilakukan selama 10 menit.

Selanjutnya acara dimulai dengan menjelaskan tentang sosialisasi kelengkapan dokumen rekam medis. Penyampaian materi dibantu dengan menggunakan infocus. Materi yang diberikan yaitu tentang kelngkapan dokumen rekam medis yang ideal dan umum dilakukan di puskesmas dan bagaimana contoh dokumen rekam medis yang lengkap.

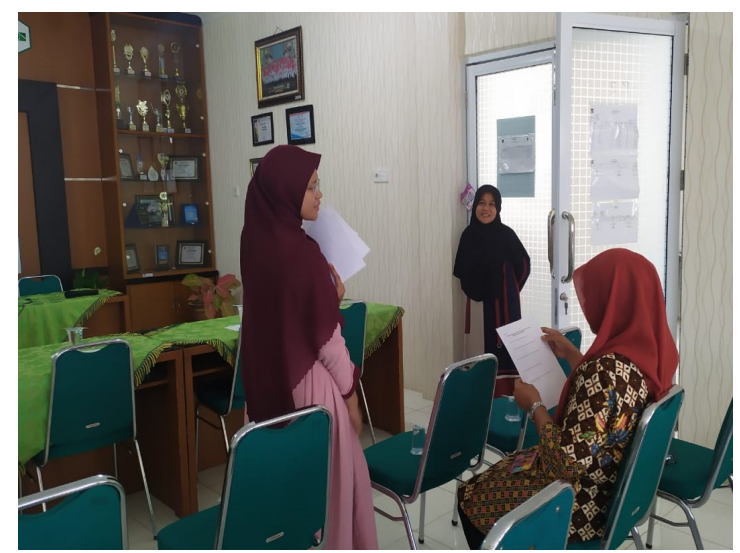

Gambar 1. Peserta mengerjakan pre test

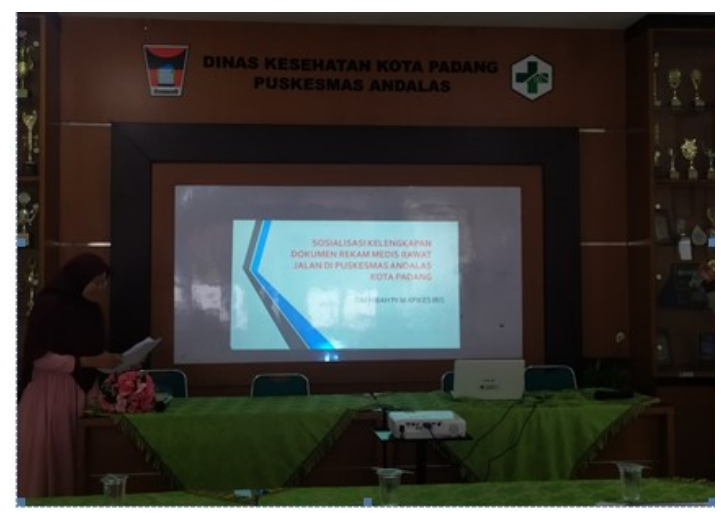

Gambar 2. Moderator memberikan penjelasan dan rangkaian acara

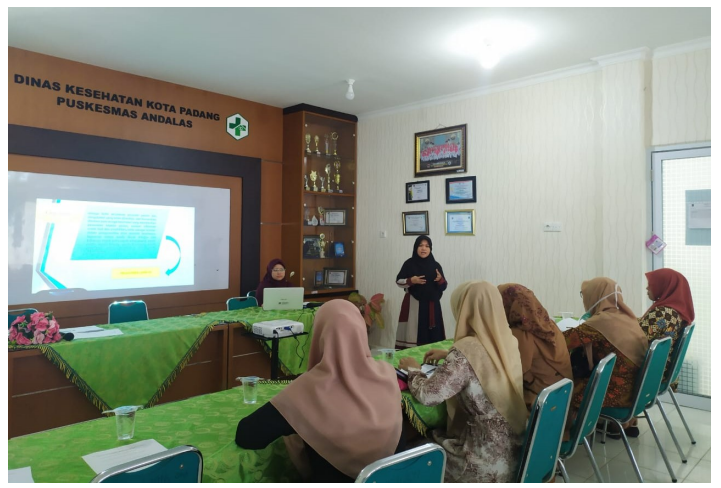

Gambar 3. Pemateri memberikan sosialisasi tentang kelengkapan isi rekam medis

Disela pemberian materi, para petugas rekam medis di puskesmas kuranji memberikan pertanyaan pertanyaan yang terkait dengan isi materi.

Secara keseluruhan, kegiatan berjalan lancar, semua peserta yang hadir mengikuti kegiatan 
dari awal sampai akhir. Peserta yang hadir sangat antusias dan aktif selama penyampaian materi dan praktek dilakukan.

Kelengkapan isi rekam medis di puskesmas Andalas juga sudah cukup baik, dan beberapa sudah menggunakan komputerisasi dalam input data pasien dan dilakukan secara terorganisir. Tim PKM juga memperlihatkan beberapa contoh formulir rekam medis yang harus dilengkapi didalam map rekam medis. Beberapa formulir yang tidak terdapat pada map rekam medis di puskesmas diberi salinanya oleh Tim PKM agar kedepannya dapat dilengkapi kembali sehingga akan tercapai isi rekam medis yang lengkap dan berkualitas.

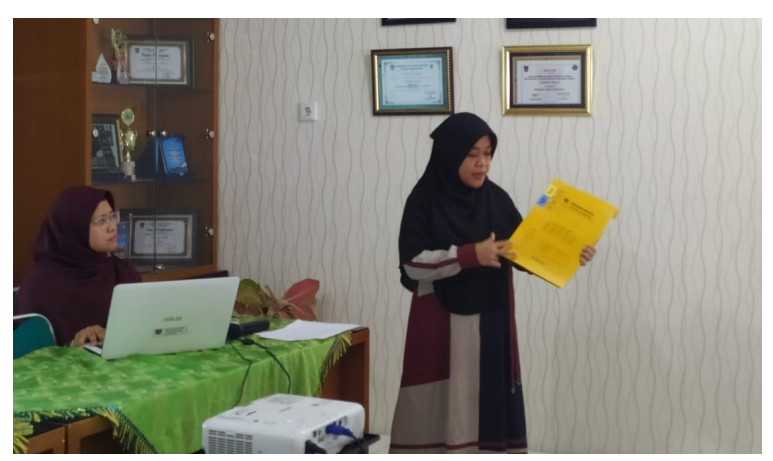

Gambar 4. Tim PKM menunjukkan contoh map rekam medis dari Laboratorium RM di Apikes Iris

Setelah dilakukan tanya jawab dan diskusi terkait kelengkapan isi rekam medis, tim PKM memberikan tugas post- test untuk melihat kemampuan peserta dalam menyerap informasi yang diberikan oleh tim. Waktu pengerjaan masih sama seperti pre test yakni 10 menit. Dari hasil post test yang diberian dapat dilihat perbandingan pemahaman peserta sebelum dan sesudah dilakukan sosialisasi. Berikut tabel hasil pre dan post test peserta sosialisasi di puskesmas Andalas Kota Padang.
Tabel 1. Perbandingan hasil pre test dan post test sosialisasi kelengkapan dokumen RM di Puskesmas Andalas Kota Padang

\begin{tabular}{|l|l|l|l|}
\hline No & Kegiatan & Total nilai & Rata-rata Nilai \\
\hline 01 & Pre Test & 1075 & 71,7 \\
\hline 02 & Post Test & 1275 & 85 \\
\hline
\end{tabular}

Dari tabel 1. Dapat dilihat pada saat peserta mengerjakan pre test, nilai yang didapat sudah cukup bagus yakni 71,7 dan setelah post test yakni 85 , ini menandakan pemahaman peserta setelah mengikuti sosialisasi tentang kelengkapan dokumen meningkat. Hal ini juga dikarenakan peserta yang mengikuti sosialisasi merupakan tenaga rekam medis puskesmas yang memiliki kualifikasi pendidikan minimal D3 Rekam Medis, sehingga pengetahuan mereka tentang pengelolaan rekam medis sangatsudah cukup baik.

Berdasarkan evaluasi dari kegiatan yang dilakukan, petugas rekam medis di puskesmas Andalas mendapatkan beberapa informasi baru terkait dengan kelengkapan isi rekam medis, dan dapat melengkapi beberapa formulir yang masih kurang didalam map rekam medis.

Kegiatan PKM diakhiri dengan foto bersama dengan petugas rekam medis, dokter dan beberpa staff puskesmas.

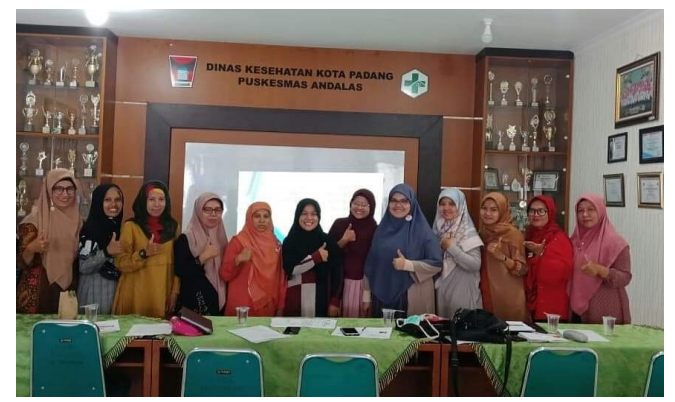

Gambar 5. Foto bersama sesaat setelah acara PKM berakhir

Kegiatan selanjutnya mitra juga meminta agar kerja sama pengabdian lebih ditingkatkan 
sehingga saling memberikan manfaat dalam pengelolaan rekam medis yang baik didalam fasilitas kesehatan.

\section{KESIMPULAN}

Kegiatan sosialisasi kelengkapan si rekam medis yang diadakan di Puskesmas Andalas Padang telah terlaksana dengan baik dan lancar. Mitra dari puskesmas Andalas Padang sangat antusias dalam mendapatkan pengetahuan tambahan tentang kelengkapan isi rekam medis, khususnya bagi petugas rekam medis. Beberapa formulir yang tidak lengkap bisa diketahui dari sosialisasi ini.

\section{SARAN}

Kegiatan sosialisasi ini diharapkan dapat memberikan pengetahuan baru dalam kelengkapan isi rekam medis dan dapat menunjang kualitas pelayanan di puskesmas Andalas Kota Padang

\section{UCAPAN TERIMAKASIH}

Tim hibah PKM mengucapkan terima kasih kepada LPPM Apikes Iris yang telah mendanai seluruh kegiatan PKM ini, dan juga terima kasih kami ucapkan kepada pihak puskesmas Andalas yang telah bersedia menerima kami dalam pelaksanaan sosialisasi ini dan Jurnal Logista Unand yang besedia mempublikasikan artikel ini.

\section{REFERENSI}

[1]. Peraturan Menteri Kesehatan Republik Indonesia Nomor 269/Per/MENKES 2008 tentang Rekam Medis. Jakarta: Menteri Kesehatan Republik Indonesia.

[2]. Huffman, Edna K., 1994. Health Information Management. America: Physicians Record Company, Berwyn Illonis

[3]. Kepmenkes RI. No 228/Menkes/SK/III/2002 tentang pedoman penyusunan standar pelayanan minimal rumah sakit yang wajib dilaksanakan di daerah. Jakarta Menkes RI.2012.

[4]. Irmawati, \& Indar. (2013). Faktor yang Berhubungan Dengan Kelengkapan Rekam Medis Di Rsud H. Padjonga Dg. NgalleTakalar 2013. Fakultas Kesehatan Masyarakat. Universitas Hassanuddin.

[5]. Rachmani E. (2010). Analisa Keterlambatan Penyerahan Dokumen Rekam Medis Rawat Inap di Rumah Sakit POLRI dan TNI Semarang. Jurnal Rekam Medis. 9 (2): 107117.

[6]. Profil Puskesmas Andalas. 2020. Tentang Kami. http/puskesmasandalas.go.id 